NASA Technical Memorandum 86805

\title{
The Role of a Real-Time Flight Support Facility in Flight Research Programs
}

Archie L. Moore

January 1986

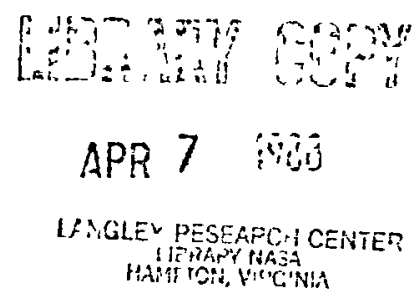

\section{N/Sก}

Natıonal Aeronautıcs and Space Admınıstratıon 
31176013245536 
NASA Technical Memorandum 86805

\section{The Role of a Real-Time Flight Support Facility in Flight Research Programs}

Archie L Moore

Ames Research Center, Dryden Flıght Research Facılıty, Edwards, Calıfornı

\section{N/Sก}

National Aeronautics and

Space Adminıstration

Ames Research Center

Dryden Flight Research Facility

Edwards, Calıfornıa 93523 
communications today between the pilot and vehicle and the ground-based test team are $11 \mathrm{mited}$ only by the capability of the facility supporting the research program in real time. The classic method of volce communications using UHF and VHF radio are still used. This method has been augmented by a wide variety of techniques. On programs such as the F-14-1X, the advanced fighter technology integration (AFTI) $F-16$, and $X-29 A$, the addition of a "hot mike" has proven to be a valuable addition to the test procedure (Fig. 5). The hot mike allows for a continuous flow of pilot comments and observations without requiring the pilot to key a transcelver. This is accomplished by transmitting the pilot's volce, by means of a pulse code modulated (PCM) stream to the ground facility. Within the facility, the PCM stream is reconverted to an analog stream and inserted into the facilities ground intercommunications network and supplied to each researcher. On the X-29A program, this concept has been carried further to include retransmission of the hot mike to safety chase vehicles by means of a volce-activated UHF transmitter. This allows chase pilots access to the same information provided to the ground test team members.

Another approach that has proven valuable to the ground test team is downilnking of the video data from the test vehicle. On the AFTI/F-16, a small charge-coupled device (CCD) camera, located in the heads-up display (HUD), has its output telemetered to the ground. The video signal is fed into the WATR video distribution system and allows the researcher in the MCC to see exactly what the pilot is viewing through the windscreen, as well as what data are being displayed on the HUD (Fig. 6). Other applications of this data acquisition technique include (1) a tail-mounted camera on an F-8 digital fly-by-wire (DFBW); (2) out-the-nose cameras on remotely piloted research vehicles (RPRV) such as the highly maneuverable aircraft technology (HIMAT) vehicle, spin research vehicle (SRV), and B-720 controlled impact demonstrator (CID); and (3) hand-held cameras in chase aircraft for the display of external phenomena that occur on the research vehicle. The upcoming F-18 high angle-of-attack program will utilize three onboard video cameras to downlink tuft patterns and 011 flows on the wing and forebody of the vehicle (Fig. 7). The F-18 application will allow researchers in the MCC to view test results in real time instead of waiting until the film has been developed. The F-18 program will also utilize a new approach to the above-mentioned hot-mike technique. The video downlink and will be used as a carrier for the hot-mike downlink and will release the PCM stream, normally used for that purpose, for downlink research data.

Probably the most far-reaching technique being utilized in the WATR is the linking of data in real time to sites across the continent by means of satelicte transmission (Fig. 8). This approach has been used on all shuttle landings at Edwards AFB. Harrier data acquired at Edwards AFB have been linked to the Naval Air Test Center (NATC) at Patuxent River, Maryland, by means of satellite to the Wallops Flight Facility and then by microwave land link to NATC. XV-15 tilt rotor data were linked from the WATR site at Ames-Dryden to the Ames Research Center processing facility at Moffett Field, Calıfornia. At present,' data acquired in real time on the $X-29 A$ are transmitted by a secure satellite link to the Grumman Aerospace Corporation facility at Calverton, New York. This approach allows the research team at the Calverton facility to participate in real time in the research flight test program. Additionally, this method of data communication has reduced data turnaround time and has subsequently resulted in a more productive flight test program.

\section{Real-Time Processing and Displays}

As depicted in Fig. 2, the increased capability required by the types of research aircraft using the WATR facility today have dictated a significant increase in real-time computation and display capability. These types of aircraft can be generically called systems-driven vehicles. They usually have large amounts of dataldownlinked to the ground test team in real time. The amount of downlinked data is so large that, without realtime computation support, the researcher would have great difficulty assimilating the data for the required real-time decisions in the $\mid M C C$. To augment the researcher's natural ability, the WATR provides real-time processing support to the MCCs at all sites. The increased number of real-time computations is depicted in Fig. 9. The ordinate value in Fig. 9 is the number of "research" words, in engineering units, delivered to the MCCs. These are words ready for interpretation by the researcher in real time.

The architecture of the telemetry and radar acquisition and processing system (TRAPS) provides a current values table of all computed and downlinked data for access by the displays in the MCCs (Fig. 10). The researcher interface to TRAPS is centered in the WATR MCCS. Two basic types of consoles are avallable in the MCCs (Figs. 11 and 12). Each MCC at Ames-Dryden is configured with six researcher consoles. Other consoles are avallable in the MCC for WATR operations, safety and vehicle operations, the flight director, and public affairs. The variety of display devices and the interactive nature of the displays allow for much flexibility for a research program.

The $X-29 A$ necessitated expanding the WATR facility to include new displays and procedures that were developed prior to the first flight of the vehicle. Cathode-ray tube (CRT) displays were developed to allow for the display of more than 400 parameters in real time by interaction with the TRAPS. Figure 13 shows several types of displays utilized by the $X-29 A$ program. As the program progressed and the envelope expansion continued, it was necessary to provide the researchers with menu selection capability for each stripchart recorder. The researcher was then able to change the parameter lineup for any recorder with a key stroke. The interactive graphics unit shown in $F_{1 g} .11$ gives the researcher the maximum flexibility. The display al lows for 64 different pages of graphic's information. Changes can be made in the parameters, scaling, plot type, color, and page layout in real time. Another feature of this console is 
the key-stroke callable least squares curve fit for cross-plots. In addition, the key stroke can average certain parameters over a maneuver. The unit can make a hard copy of any page on the CRT, and any page can be distributed to any other console in the MCC.

One of the most cost-effective functions avallable in the MCC was developed for the F-15 program. This function allows the researcher to uplink computed values to the research vehicle (Fig. 14). The function requires special uplink equipment on the research vehicle and the cockpit displays. When the program is operating in this mode, downlinked data values are used to create computed values that are then uplinked to the vehicle in the form of error signals. The algorithms and vehicle displays are developed in the simulation facility. Prior to its development, the pilot had to perform the function using standard cockpit instrumentation. A conservative estimate of the F-15 project pilot was that, by utilizing this function, the required number of test flights was reduced by 50 percent.

The researcher can interact with the real-time computation to change equation coefficients and parameter values depending on the test point desired for a given maneuver. Given the high cost of flight test time, any function that can optimize the data collected has a significant positive impact on program cost and schedule.

\section{Tracking and Data Acquisition}

The WATR has an ongorng development program to insure the most accurate downlink data avallable in real time. High-gain tracking antenna systems and precision tracking radars are used to acquire the optimum data signal. Research vehicles such as the remotely piloted HoMAT (FIg. 15 ) require continuous uplink and downlink communications at all times at all aircraft altitudes during flight.1 To accomplish this, two antennas were installed on the vehicle. The PCM downlink was transmitted on two different frequencies, one from each antenna.

Th1s approach takes advantage of the frequency polarization feature of the telemetry autotracking antenna system. Complete radiation coverage is obtained by tuning one recerver to each frequency and using the combing feature of the antenna system. The outputs of the two receivers are combined in proportion to the relative signal strengths to present one PCM bit stream or video output to the ground decommutation station. This approach contributed very much to the success of the flight research program.

One of the most demanding tracking and data acquisition tasks undertaken by the WATR was that required for the $B-720$ controlled impact demon- strator (CID). 2 Although no feedback paths from the airplane were necessary to be closed on the ground, precision C-band tracking radar (FPS-16) played a significant role in obtaining the final impact. Manual tracking through visual alds was used to overcome multipath problems. Accuracy could have been improved by using a microwave landing system (MLS). Nevertheless, the final impact was a success, and much valuable information was derived from the impact demonstration. The CID required all WATR tracking and data acquisition systems during each flight mission (F1g. 16). The nature of the project required redundant systems whenever possible.

For precision tracking information in a normal airfield environment, the WATR uses its facilities at Crows Landing in northern California (Fig. 17). The MLS and a laser tracker allow the research vehicle to obtain and use, as required, very precise space position information in a terminal area situation. The integration of these two tracking devices with the $\mathrm{X}$-band radars located at Crows Landing gives the research program the full spectrum of space position information in the MCC.

\section{Concluding Remarks}

The NASA Western Aeronautical Test Range continues to $1 \mathrm{mplement}$ approaches and systems to increase the productivity of research flight test. New interactive graphics systems are now under development to enhance the existing capabilities. The installation of new satellite systems will enhance the ability to transmit data from remote test sites to centralized mission control centers (MCCS). The combination of these new satellite systems with existing systems such as the global positioning system (GPS) and the tracking data relay satellite system (TDRSS) will greatly increase the flexibility and productivity of future flight test programs (Fig. 18). The ability to acquire data, track a research vehicle, maintain real-time communications with the research vehicle, and provide comprehensive realtime information in an integrated MCC will insure the close partnership between the research program and the ground-based facility in the future.

\section{References}

1Harney, Paul F., "Diversity Techniques for Omnidirectional Telemetry Coverage of the HoMAT Research Vehicle," ITC Paper, International Telemetry Conference, San Diego, California, Oct. 13-15, 1981.

2Kempel, Robert $W_{.}$, and Horton, Trmothy W., "Flight Test Experience and Controlled Impact of a Large, Four-Engine, Remotely Piloted Airplane," NASA TM-86738, 1985. 
Provide capability for the conduct of aeronautical flight research through. . .
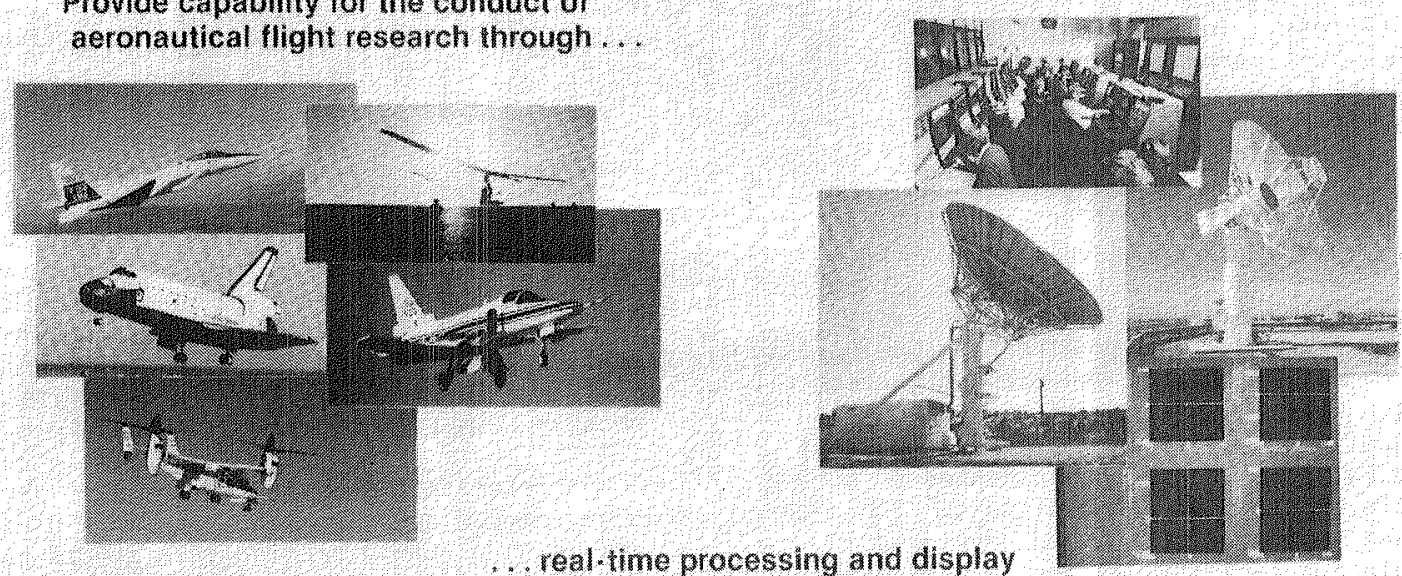

. real-time processing and display systems, racking systems, and communications systems

Fig. 1 Western Aeronautical Test Range mission.

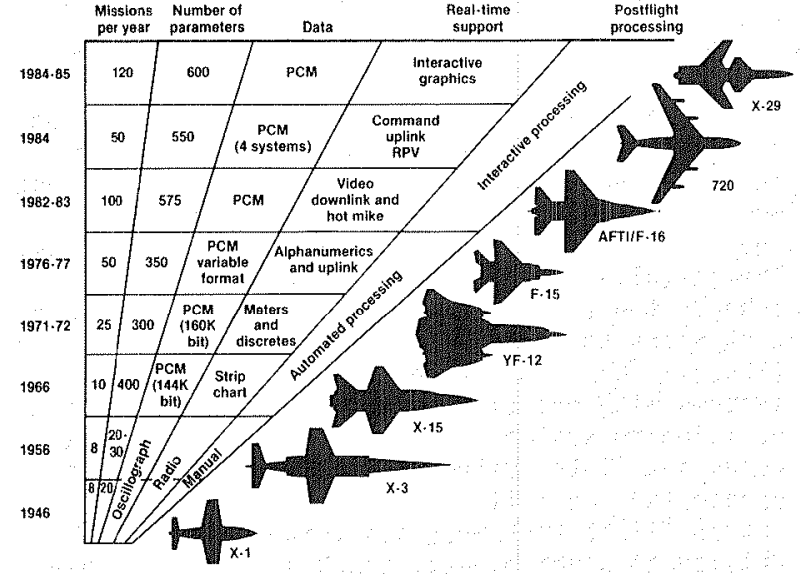

Fig. 2 Evolution of Ames-Dryden aeronautical research program requirements. (For vehicle depicted, number of missions per year includes flights, combined systems tests, and engine muns.)

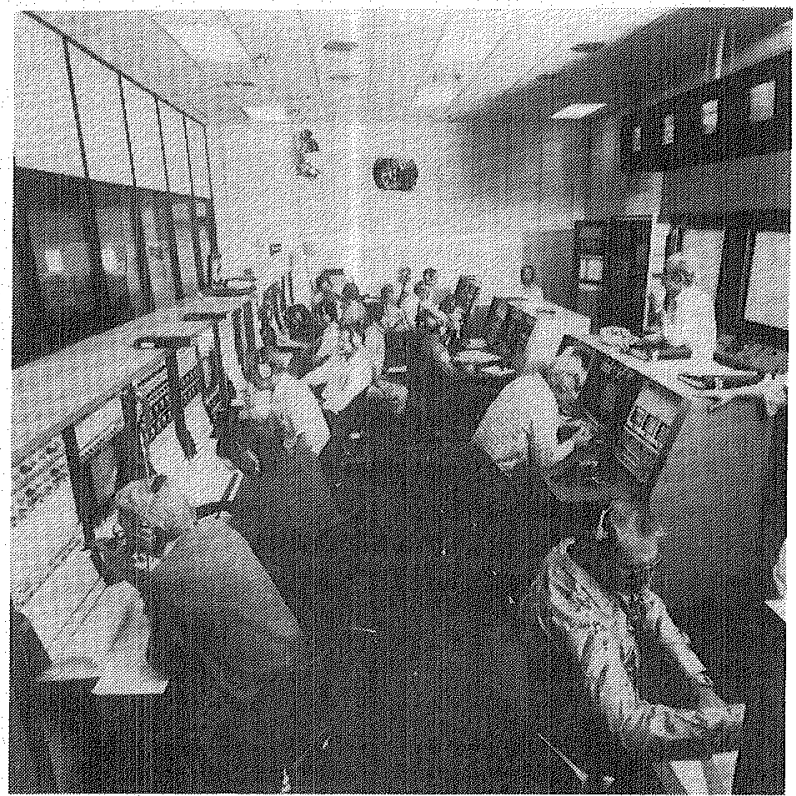

ECN 20640

Fig. 3 Mission control center at Western Aeronautical Test Range. 


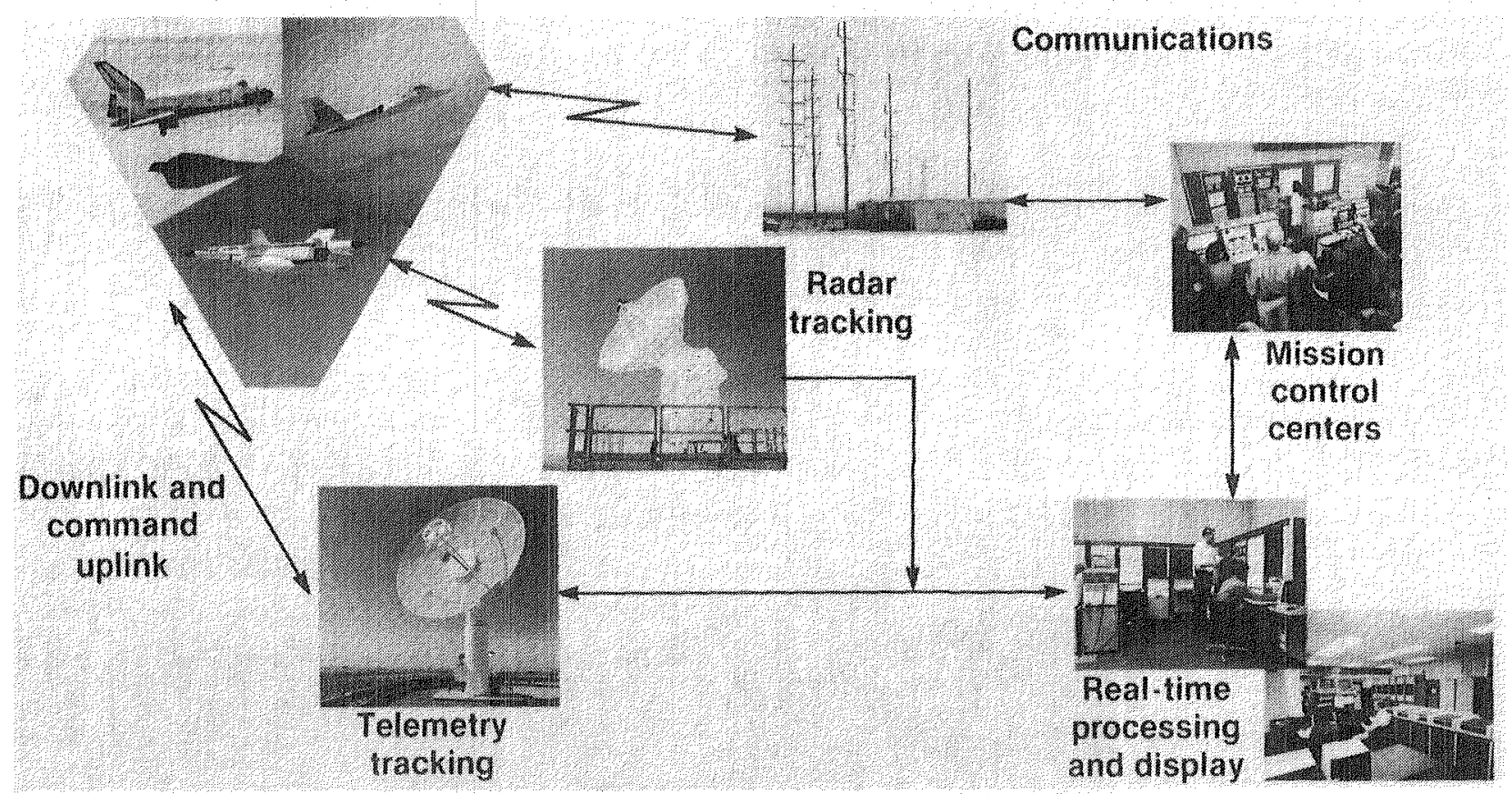

Fig. 4 Basic real-time ground support facility capability for support of research and flight test requirements.

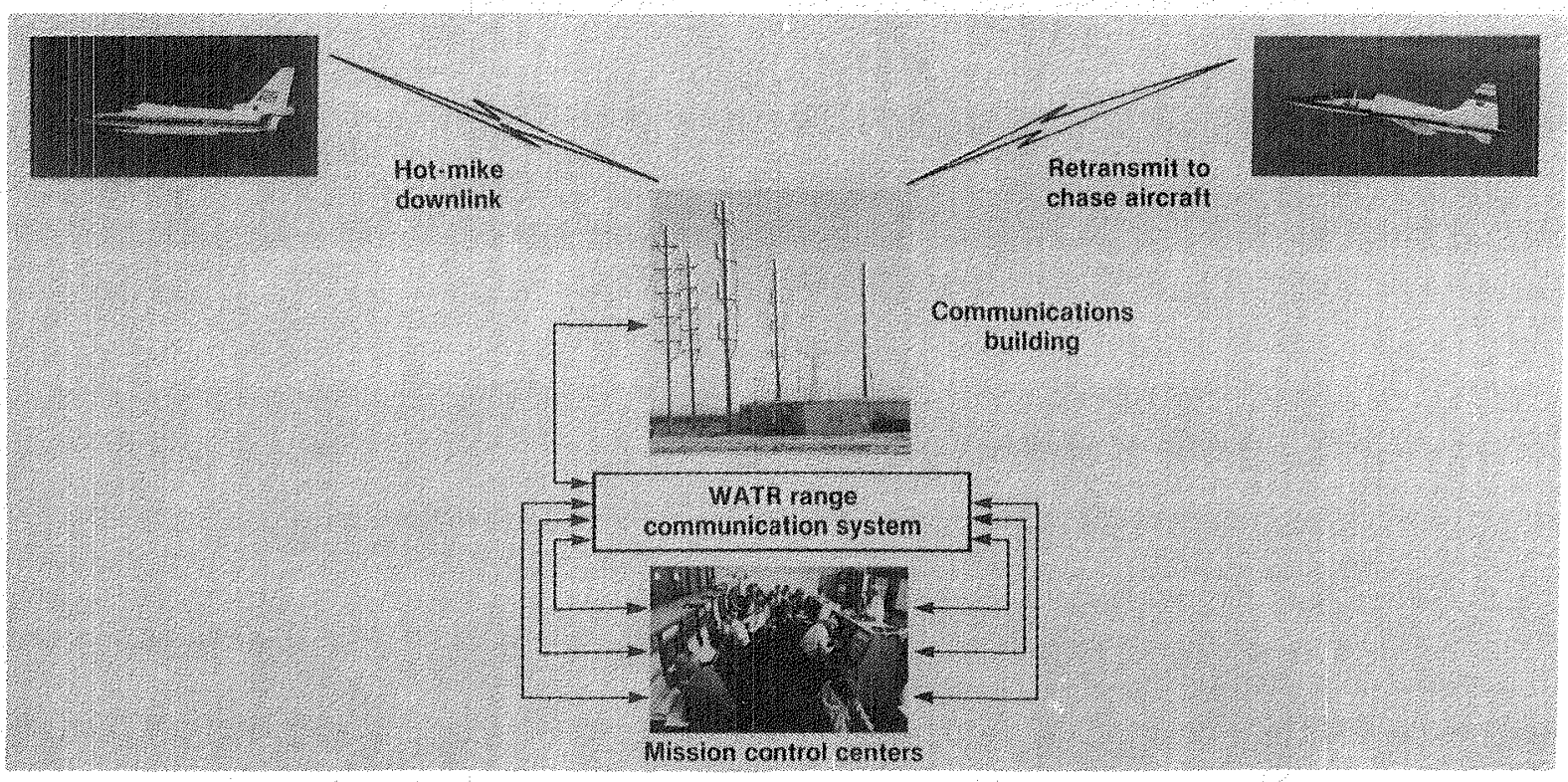

Fig. 5 Typical flight research program and communications network. 


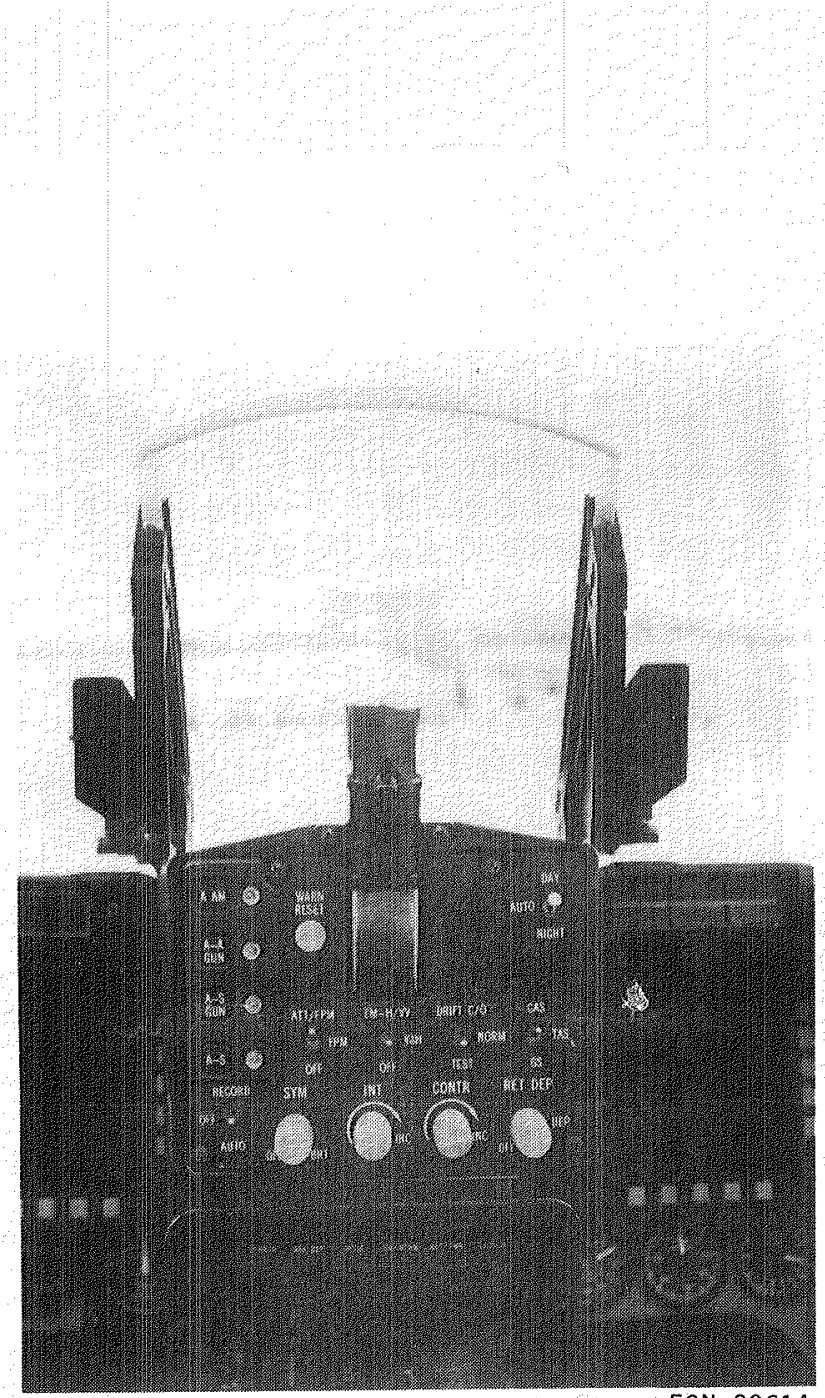

ECN 20614

Fig. 6 Heads-up display.

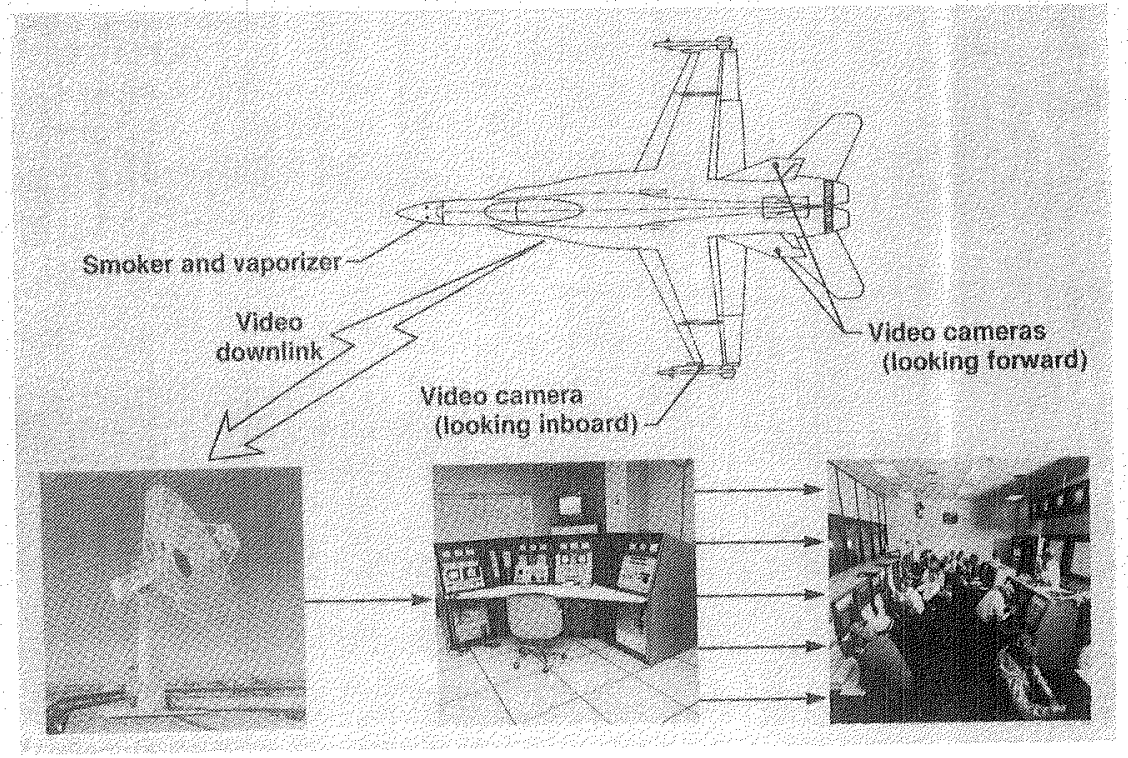

Fig. 7 F-18 real-time flow visualization techniques. 


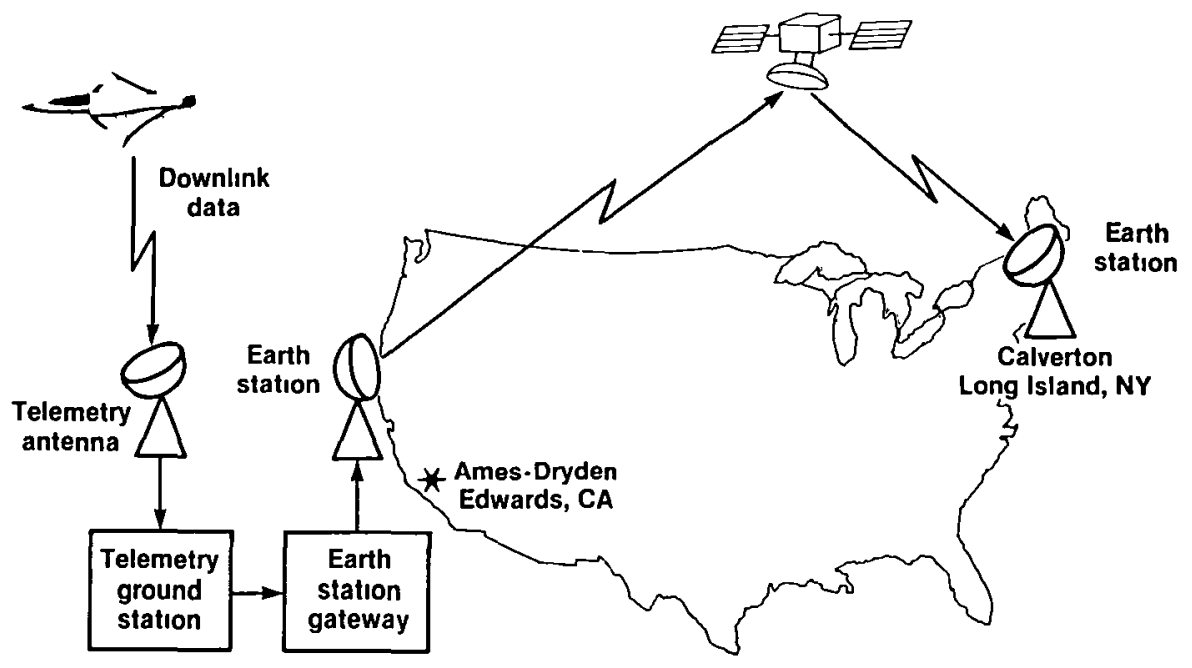

Fig. 8 X-29A transcontinental data link.

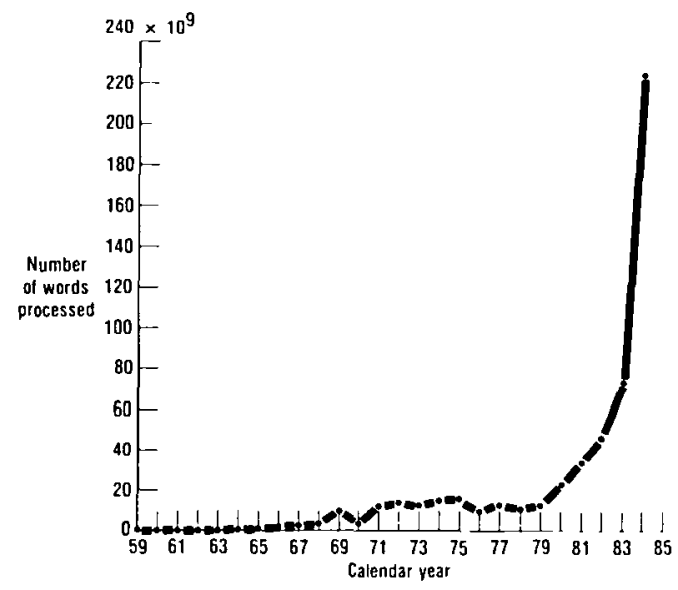

Fig. 9 Total number of real-time computations. (Unified tracking and data acquzsition capability attained in 1985.)

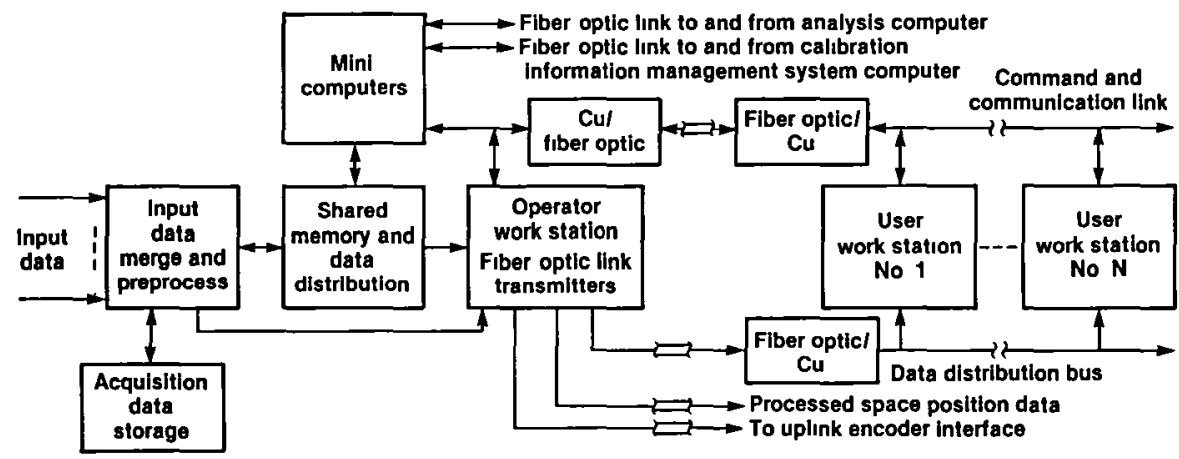

Fig. 10 Real-time data processing and display system. 


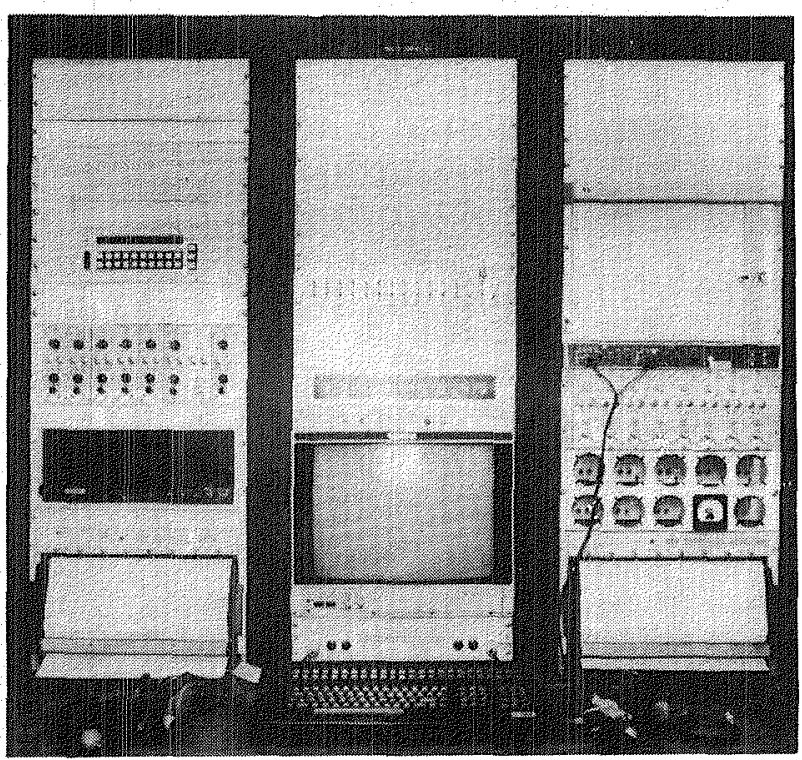

ECN 31788

Fig. 11 Blue room analyst console No. 1 in WATR mission control center.

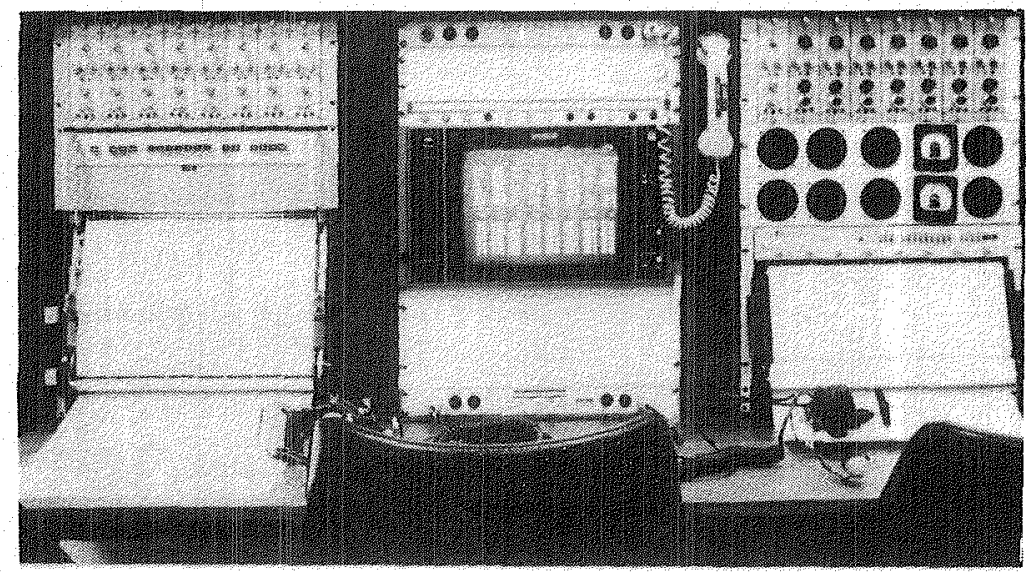

Fig. 12 Blue room analyst console No. 3 in WATR mission control center. 


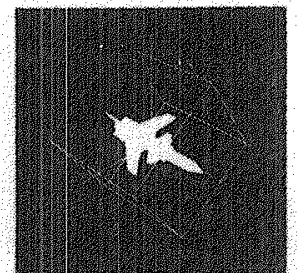

Vehicle altitude

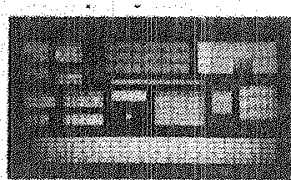

Failure status monilor

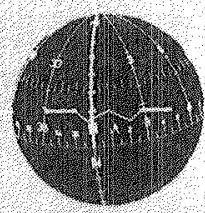

Cockoil instruments

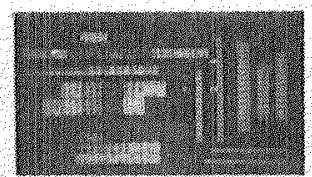

Fight controller display

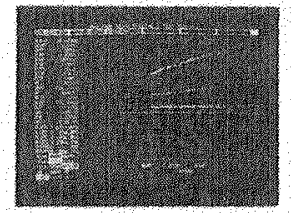

Interactive graphics display.

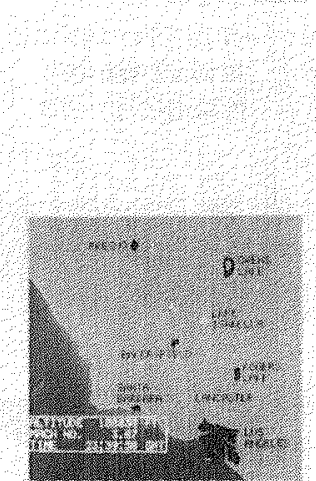

Space position

Fig. 13 Real-time interactive displays.
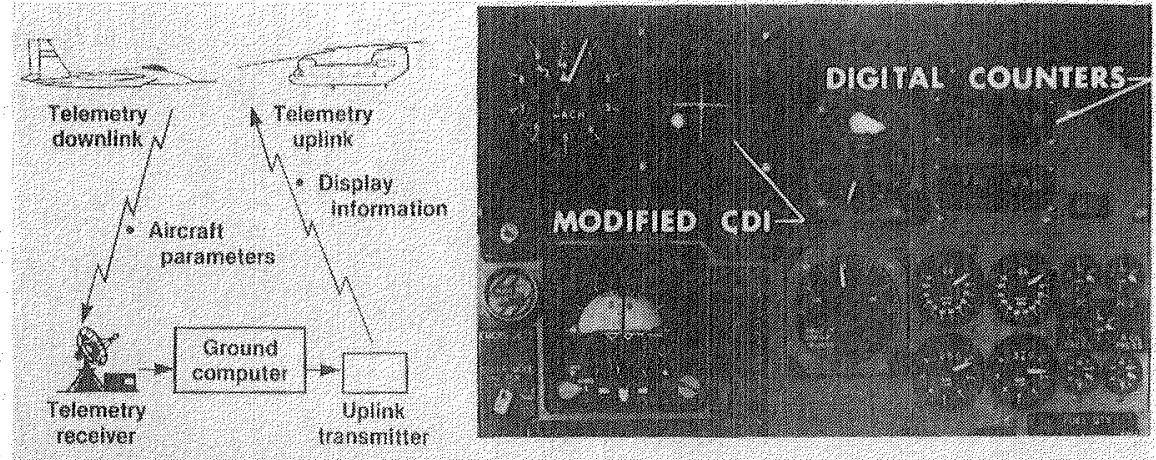

Cackpit display with computed displays noted

- Ground computer generates display intormation

- Algorithms developed on simulalor

Fig. 14 Remotely computed display. 


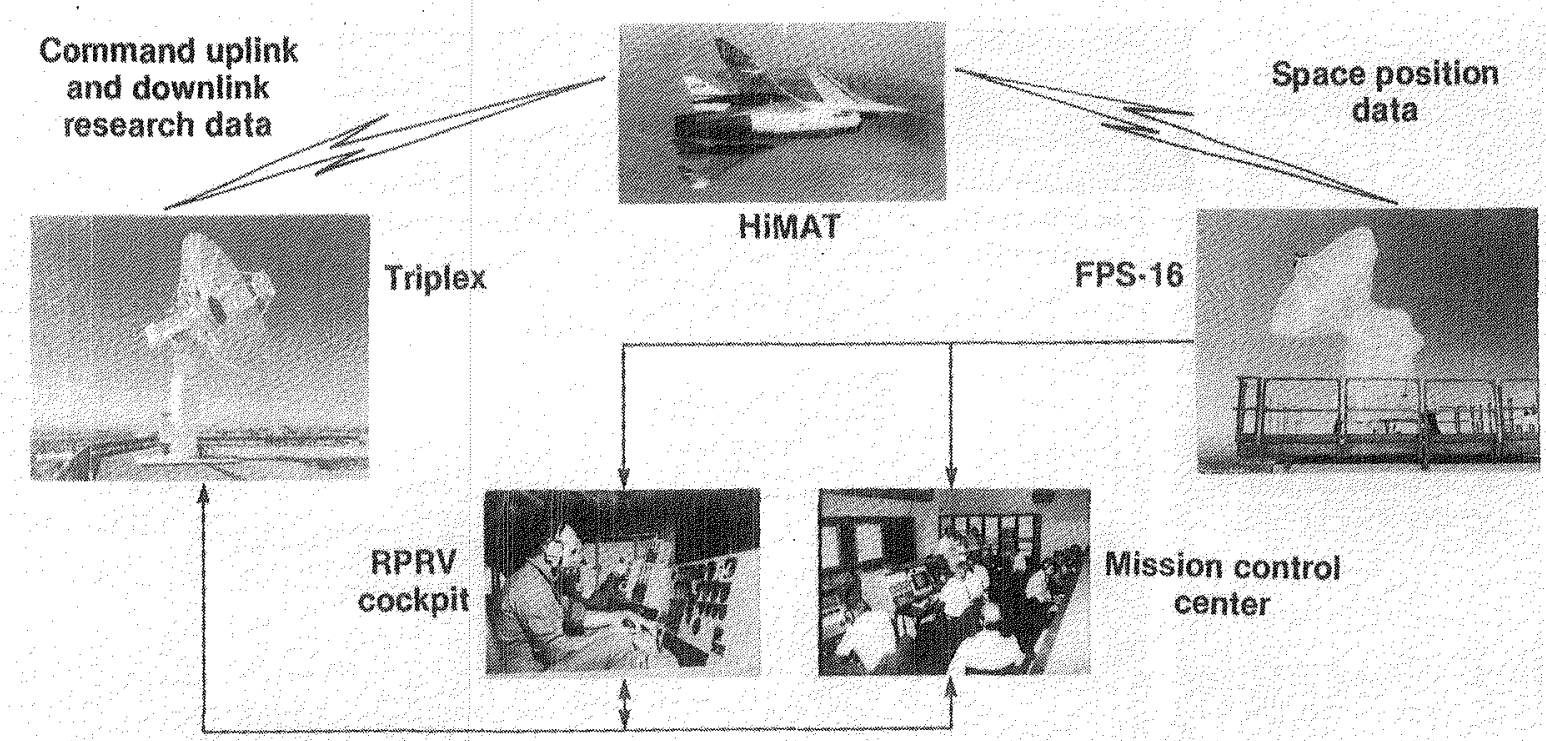

Fig. 15 Tracking and data acquisition requirements for highty maneuverable aircraft technology.

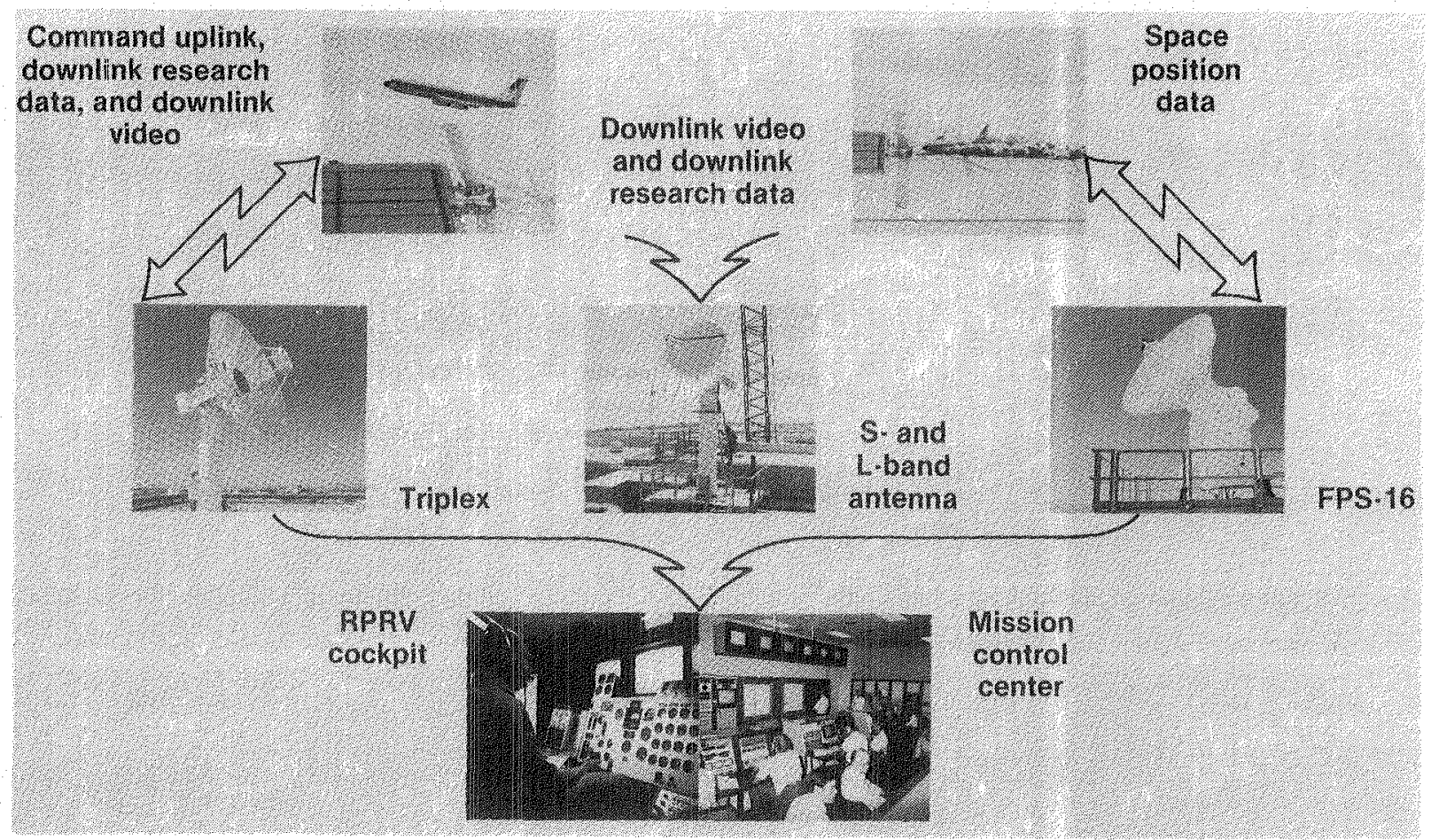

Fig. 16 Tracking and data acquisition requirements for controlled impact demonstrator. 


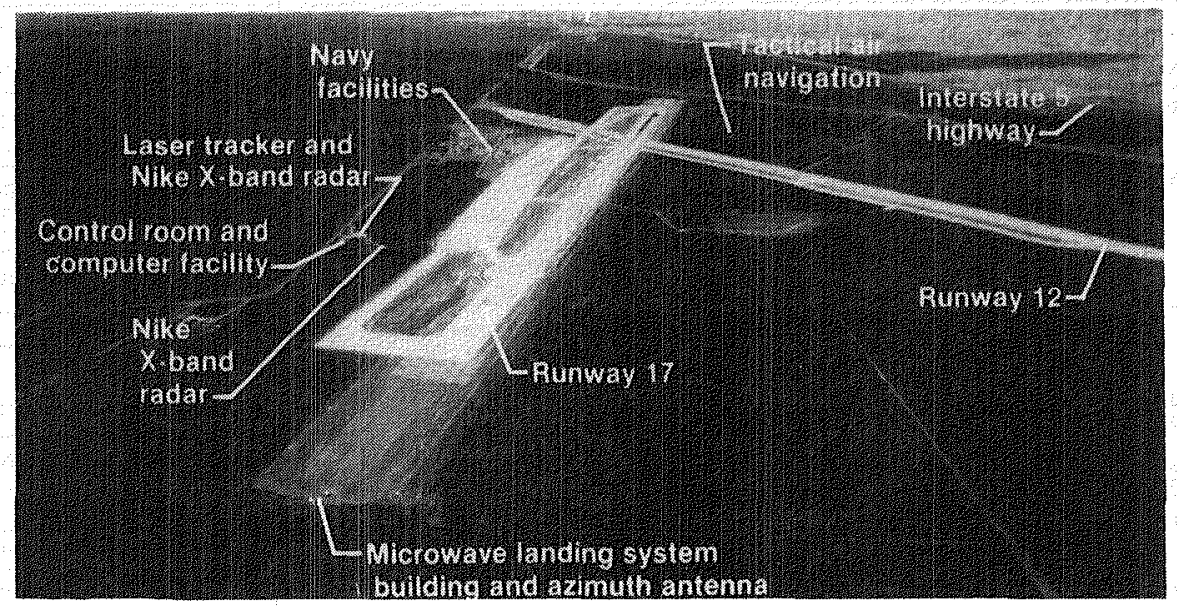

Fig. 17 WATR precision tracking facility at Crows Landing in northern California.

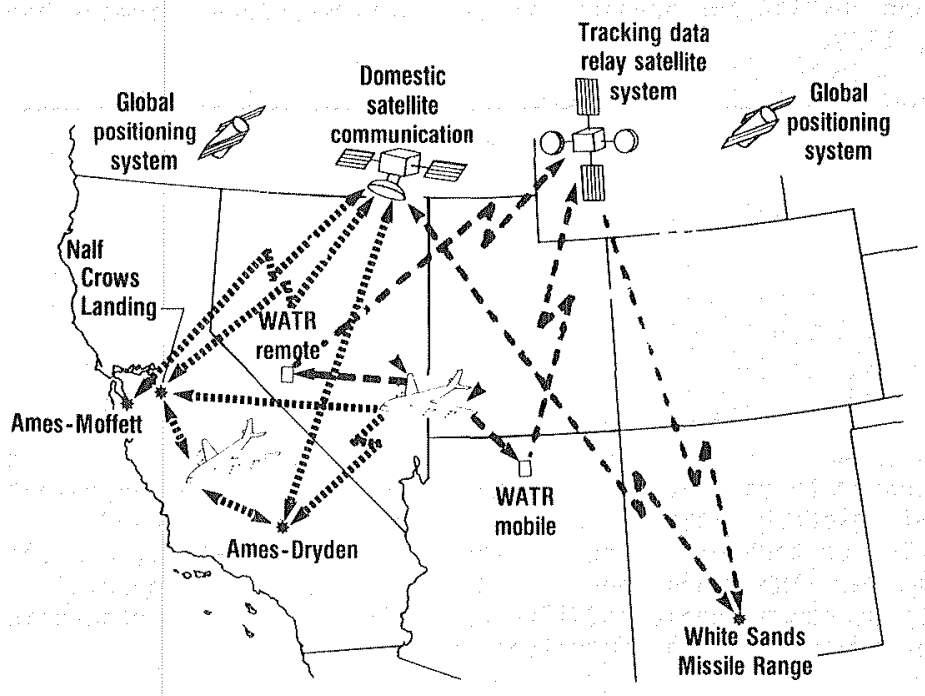

Fig. 18 Future network possibilities. 


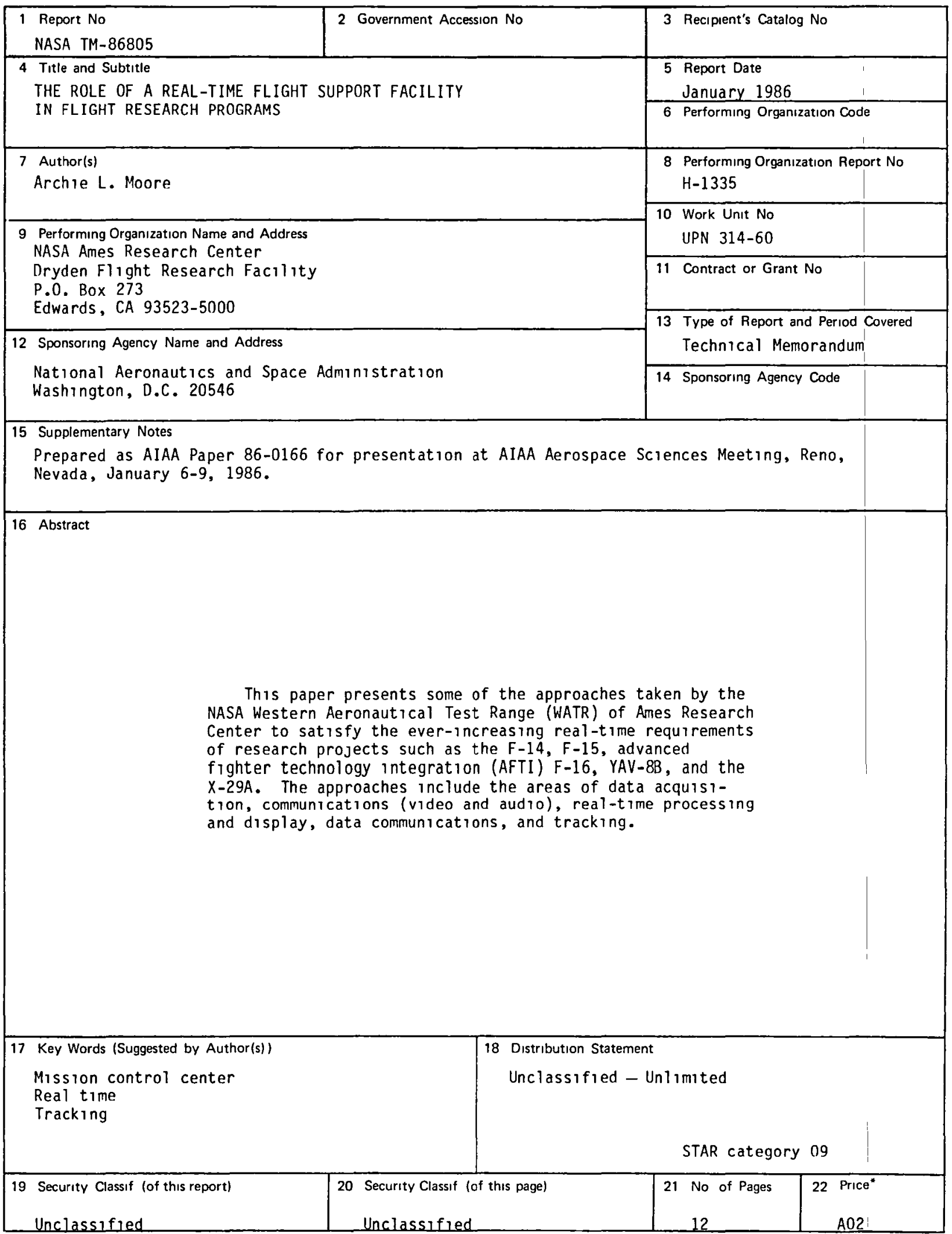

*For sale by the National Technical Information Service, Springfueld, Virginia 22161. 


\section{End of Document}

